Rapid Reviews COVID-19•

\title{
Reviews of "Estimating Data-Driven COVID-19 \\ Mitigation Strategies for \\ Safe University Reopening"
}

Hanisha Tatapudi ${ }^{1}$, Xiang Chen, Ph.D.; ${ }^{2}$

${ }^{1}$ University of South Florida, Industrial Engineering, UNITED STATES,

${ }^{2}$ Assistant Professor, University of Connecticut, UNITED STATES

Published on: Sep 19, 2021

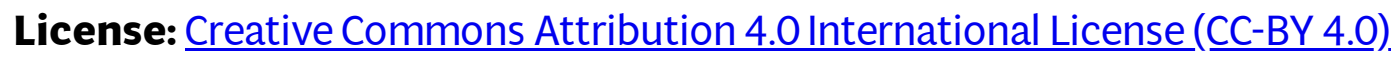


To read the original manuscript, click the link above.

Summary of Reviews: Reviewers find that this preprint offers a straightforward model to explore university re-opening--with important "micro-scale" policy implications--but offer a number of suggestions to further refine and clarify the model's construction and parameters.

\section{Reviewer 1 (Hanisha Tatapudi) |}

\section{Reviewer 2 (Xiang Chen, Ph.D) |}

$$
\begin{aligned}
& \text { RR:C19 Strength of Evidence Scale Key }
\end{aligned}
$$

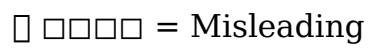

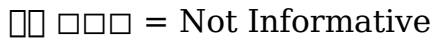

$$
\begin{aligned}
& \text { प्रा पि = Potentially Informative }
\end{aligned}
$$

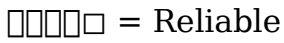

$$
\begin{aligned}
& \text { प्राप्र = Strong }
\end{aligned}
$$

To read the reviews, click the links below. 